\title{
Biopsy of Pancreas
}

National Cancer Institute

\section{Source}

National Cancer Institute. Biopsy of Pancreas. NCI Thesaurus. Code C51671.

Removal of tissue from the pancreas for microscopic examination. 